\title{
Comparison of Xiao Gang's Parallel Proses Compiled by Mei Dingzuo and Zhang Xie
}

\author{
Hualin Mou \\ HeZhou University, Hezhou, 542899, China
}

Keywords: Mei Dingzuo; Zhang Xie; Xiao Gang's parallel proses; Compilation; Comparison

\begin{abstract}
There are two differences in Xiao Gang's parallel proses compiled by Ming Dynasty's Mei Dingzuo and Zhang Xie: the first is the different numbers of parallel proses compiled; the second is the different attribution of literature genre of parallel proses compiled. The reason for the differences is that they were based on different literature materials and literature genre standards. Such differences also reflect the advantages and disadvantages of Xiao Gang's parallel proses compiled by them.
\end{abstract}

\section{Introduction}

Mei Dingzuo and Zhang Xie are different individuals so the Xiao Gang's parallel proses compiled by them are different: the first is the different numbers of parallel proses compiled; the second is the different attribution of literature genre of parallel proses compiled. The reason is that they were based on different literature materials and literature genre standards. Such differences also reflect the advantages and disadvantages of Xiao Gang's parallel proses compiled by them. To reveal such differences and understand both their advantages and disadvantages helps to research Xiao Gang's proses.

\section{Differences in Numbers Compiled and Attribution of Literature Genre}

Xiao Gang's parallel proses compiled by Mei Dingzuo are recorded in Volume 2 of Liangwenji and Volume 21 of Recording of Proses for the Past Dynasties. According to the writer's statistics, the Volume 2 of Liangwenji records 117 of Xiao Gang's parallel proses; the Volume 21 of Shiwenji records 69 of Xiao Gang's parallel proses; the total number of Xiao Gang's proses recorded in the two books are 186, which are distributed in the 22 literature genres classified by Mei Dingzuo. The details are listed below (the figures within the brackets are the number of parallel proses recorded in Shiwenji):

7 imperial decrees; 6 orders; 9 orders [1]; 1 early parallel-style prose; 18 memorials to an emperor in ancient times [1]; 1 memorial to the throne; 2 literature writings; 50 notes [25]; 23 letters [8]; 13 prefaces [4]; 1 statement; 1 Qi genre; 5 sacrificial songs [5]; 17 inscriptions [12]; 3 steles; 3 anadiplosis proses; 14 epitaphs [5]; 1 eulogies; 1 lament; 5 articles [5]; 2 funeral orations; 3 pieces of Shu [3]

It can be seen that the 117 parallel proses recorded in Liangwenji are distributed in 19 literature genres and the 69 parallel proses recorded in Shiwenji are distributed in 10 literature genres. However, why did "Shu" appear in both books? After investigation, the writer founds that it is because the contents of "Shu" are different: Memorial to the Throne Written by Tiao Zhitu states government affairs and is thus collected in Liangwenji; Memorial for the Benefactors of All Temples, Memorial to the Eight-feet Man-made Dry-lacquer Golden Buddha and Memorial to the Man-made Temple, all of which state the Buddhist ceremonies, are collected in Shiwenji. But whatever the content is, the literature genre is "Shu”, so Mei Dingzuo shouldn't distinguish them and all the parallel proses under "Shu" shall be combined together. Mei Dingzuo even divided "article" and "funeral oration" into two types, which is actually not necessary. Although the objects of "article" and "funeral oration" are different, "funeral oration" belongs to "article, so the two types shall belong to one classification. 
Xiao Gang's parallel proses compiled by Zhang Xie, which are collected in the Complete Works of Seventy Two Poets . Collection Made by the Order of Emperor Jianwen of Liang, and are different from those compiled Mei Dingzuo in the two aspects: firstly, although the literature genre continued the Mei Dingzuo's classification, a genre of “Ode” was added (the genres of Xiao Gang's proses were divided into 23 genres by him); secondly, he made adjustments to the proses collected under each genre by Mei Dingzuo. According to the writer's statistics, Collection Made by the Order of Emperor Jianwen of Liang collects 192 pieces and the literature genres are distributed below (the figures within the brackets are the number of pieces collected under the genres by Mei Dingzuo):

21 pieces of ode [No this genre in Mei Dingzuo's compilation], 3 imperial decrees [7]; 5 orders [6]; 9 orders; 1 early parallel-style prose; 18 memorials to an emperor in ancient times [1]; 1 piece of Shu; 2 literature writings; 49 notes [50]; 19 letters [23]; 7 prefaces [13]; 2 statements [1]; 1 Qi genre; 5 sacrificial songs; 12 inscriptions [17]; 8 steles [3]; 3 anadiplosis proses; 14 epitaphs; 1 eulogies; 1 lament; 5 articles; 2 funeral orations; 3 pieces of Shu [3]

It can be seen that Zhang Xie made some adjustments for the number of parallel proses under some literature genres compiled by Mei Dingzuo. The first adjustment is reduction: the number of imperial decrees was reduced from 7 to 3; the orders were reduced from 6 to 5; the number of "notes" was reduced from 50 to 49; the number of letters was reduced from 23 to 19; the number of prefaces was reduced from 13 to 7 ; the number of inscriptions was reduced from 17 to 12; the total number reduced was 21; the second adjustment is increase: a net increase of the pieces of "ode" was 21; the number of epitaphs was increased from 3 to 8; the number of statements was increased from 1 to 2; the total number increased was 27. Based on the 186 parallel proses collected by Mei Dingzuo, Zhang Xie added 27 and reduced 21, so there were actually 192. For the literature genres, Zhang Xie added the genre of "ode", which showed that he was more brilliant than Mei Dingzuo, because he completed the types of parallel proses written by Xiao Gang; more importantly, the 21 pieces of ode made up for the serious defect in the entire omission of Xiao Gang's ode in Mei Dingzuo's Liangwenji so that Xiao Gang's ode, which was submerged in all types of literatures, can be shown to the world as a whole and this also offered extremely precious materials for the later generations to research Xiao Gang's ode achievement.

\section{Reasons for Differences and Advantages and Disadvantages of Compilations}

Why there are differences between Xiao Gang's parallel proses compiled by Mei Dingzuo and Zhang Xie? After detailedly comparing the proses collected under each genre, the writer found that the principal reason is that they were based on different literatures and genre standards respectively. The so-called different genre standards are that a same prose is classified into different genres by different compilers. For instance, the A Letter for Acknowledging Princess Anji's Reward to the Hu People was collected in the genre of "letter" by Mei Dingzuo; however, the A Note for Acknowledging Princess Anji's Reward to the Hu People was collected in the genre of "Note" by Zhang Xie. This shows the difference genre standards for a prose. The above reasons and the advantages and disadvantages of Mei Dingzuo and Zhang Xie were different in each genre; the writer will indicate them according to their genres in comparison.

Ode: Mei Dingzuo lacked the genre of “ode” and only the prefaces of Ode of Golden Musical Instrument, Ode of Regret and Ode of Pack with Eye-Brightening Dew were collected in the genre of "Preface"; Zhang Xie collected all of Xiao Gang's 21 pieces of odes, which are respectively: Ode of Regret (with Preface), Home-returning Ode, Shuju Ode, Xuchou Ode, Ode of Prince Xuanxu, Tongue Ode, Ode of Deep Spring, Ode of Great Gully, Ode of Besieged City, Ode of Dance, Ode of Chinese Zither, Ode of Golden Musical Instrument (with Preface), Ode of Candles, Ode of Lamps, Another Ode of Lamps, Ode of Pack with Eye-Brightening Dew (with preface), Ode of Plum Blossom, Ode of Lotus Picking, Ode of Tall Bamboos, Ode of Mandarin Ducks, Ode of Chinese Pond-heron. Why Mei Dingzuo lacked the genre of “ode"? Liangwenji Abstract says that "The 14 volumes in Liangwenji gathered the proses in Liang Dynasty and many of them were extracted from the Book of Liang Dynasty, History of Southern Dynasties and many other works.” According to this, 
we know that Mei Dingzuo didn't refer to historical records and collected works, so he didn't collected the Xiaogang's odes recorded in such books, causing the lack of the whole genre. Besides, according to Collection Made by the Order of Emperor Jianwen of Liang . Note 3 which states that “There are not many perfect systems”, it thus can be seen that Zhang Xie's collection got involved in many books of Tang and Song Dynasties, so the Xiao Gang's odes recorded in these books can be covered. Therefore, the difference in literature references resulted in the difference in the genres and total number of Xiao Gang's parallel proses collected by them. Although Mei Dingzuo didn't collect the genre of “ode”, he brought prefaces of Ode of Golden Musical Instrument, Ode of Regret and Ode of Pack with Eye-Brightening Dew in the Preface, which means that he knew Xiao Gang's odes. But why did he abandon "ode"? The writer guesses that Mei Dingzuo thought that "ode" and "article" belonged to different literary forms and he chose "article" by abandoning "ode". To collect the prefaces of Ode of Golden Musical Instrument, Ode of Regret and Ode of Pack with Eye-Brightening Dew means that he separated ode and preface to conform to the article. Actually, this neglected the organic unification of the two genres and destroyed the entirety of an ode, so it is not advisable. Furthermore, as a matter of fact, there are 20 pieces of the Xiao Gang's odes collected by Zhang Xie, because the Ode of Lamps and Another Ode of Lamps compiled by him were integrated into Collected Odes of Lamps in Volume 80 of Collected Works of Arts and Proses. Zhang Xie took it as another ode from "Jiu wei jian tu" and thus named it "Another Ode of Lamps". Besides, those compiled by Zhang Xie had more sentences like "southern rape flower, western paint, sunlight mixed, and reflection clear" in today's Collected Works of Arts and Prosesi. This is because that the Collected Works of Arts and Proses known by Zhang Xie had such sentences. It is thus can be seen that Zhang Xie considered ode preface as a part of "ode” and collected Xiao Gang's odes into the “odes”, so he avoided Mei Dingzuo's shortcoming of dismembering the proses arbitrarily and he offered significant materials for the overall research of Xiao Gang's parallel proses. For this, the parallel proses compiled by Zhang Xie were better than those compiled by Mei Dingzuo.

Imperial decrees: The 7 imperial decrees compiled by Mei Dingzuo are the Enthronement Decree, Decree of Releasing the Former North People, Decree of Changing the Name of Period into Dabao, Decree of Lifting Restrictions, Decree of Burying Queen Jian, Decree to Brother Jiang Ziyi, Modified Imperial Decree of Abdicating to Yuzhang King Dong, Decree of Lifting Restrictions. Zhang Xie didn't collected the Decree of Releasing the Former North People, which was written by Hou Jing after textual research by Zhang Xie, Decree to Brother Jiang Ziyi, which was written by Emperor Liangwu after textual research by Wu Guangxing in Xiao Gang and Xiao Yi Chronicles, which says: "On November 6 of the second year of Taiqing period, Jiang Ziyi, the Military Officer of Nanjin, together with his two brothers opened the Chengming Door to go out to fight the enemy and died. According to the Decree to Jiang Ziyi, Volume 4 and 5, the Collected Works of Liang Dynasty belong to the Emperor Jianwen in Volume 9. When Ziyi etc. died, the imperial decree should be issued by the Emperor Liangwu. Therefore, the decree should be changed under the name of the Emperor Liangwu in Volume 3 of the Collected Works of Liang Dynasty. ii”. Modified Imperial Decree of Abdicating to Yuzhang King Dong (see Book of Liang Dynasty . Biography of Hou Jing and History of Southern Dynasties . Liangbenji II) was written by Hou Jing at that time but was collected under the name of Xiao Gang in Liangwenji. Mei Dingzuo indicated: "Hou Jing imprisoned the Emperor Jianwen, modified to imperial decree to abdicate to Prince Zhaoming, (Xiao) Dong; he forced the emperor to write the decree himself; when writing to this part, the emperor cannot stop sobbing.” Mei's indication came from his misreading of the History of Nan Dynasties. As written in the History of Nan Dynasties, “(Hou Jing) modified the imperial decree, letting the by-blow to be the lineal descent, and forced the emperor to abdicate to Yuzhang King (Xiao) Dong; Lv Jilue was ordered to sent the decree to the emperor and forced him to write the decree; when writing that "the deceased emperor considered the importance and steadiness of the country, he abdicated to the second son", the emperor couldn't stop sobbing." Therefore, this decree was actually written by Hou Jing because he just forced Xiao Gang to copy it; it shall thus belong to Hou Jing. That Zhang Xie was able to delete the proses wrongly collected under the name of Xiao Gang shows that his knowledge and experience and the parallel proses compiled by him were better than those compiled by Mei Dingzuo. However, the 
Decree of Lifting Restrictions, which was recorded in the Book of Liang Dynasty . Records of Emperor Jianwen, was undoubtedly written by Xiao Gang. Why Zhang Xie didn’t collected it. This reveals the shortcoming of the compilation of Zhang Xie.

Orders: Mei Dingzuo compiled the following 6 orders, which are respectively Order for the Death of Kong Xiuyuan, Order to Xiangdong King, Another Order to Xiangdong King, Order to Hengshanhou Gongshou, Order to Liu Xiaoyi, Order for Tingsheng Lincheng Grand Duchess Seeing the Imperial Concubine. Zhang Xie Didn't collected Another Order to Xiangdong King. According to the Book of Liang Dynasty . Biography of Xiao Zixian, which states: “Taizong ordered Xiangdong King that Wang Jun was original an old heeler and then taught Xiao Kai and was called a gifted scholr.”, therefore, the Another Order to Xiangdong King was actually written by Xiao Gang. Zhang Xie didn't collect it so Mei Dingzuo was better in this genre.

Notes: Mei Dingzuo compiled the Note for Letting the Prisoners with Slaves and Notes for Memorials Submitted on the Lecturing Date, both of which were not collected by Zhang Xie, who only compiled A Note for Acknowledging Princess Anji's Reward to the Hu People, which was not collected by Mei Dingzuo. According to that Note for Letting the Prisoners with Slaves and Memorial to the Throne Written by Tiao Zhitu were supposed to be one piece, it was improper for Mei Dingzuo to divide it into two pieces. According to Mei Dingzuo’s note, Notes for Memorials Submitted on the Lecturing Date can be called the Note for Appreciating the Lecture of Prajna Paramita, so this note and the Note for Appreciating the Lecture of Prajna Paramita, so this note and were supposed to be one piece. It is strange why it was divided into two pieces. A Note for Acknowledging Princess Anji's Reward to the Hu People was correctly compiled into the genre of "letters" by Mei Dingwen because it can be proved in the Volume 35 of Collected Works of Arts and Articles, which records the A Letter for Acknowledging Princess Anji's Reward to the Hu People. We don't know why Zhang Xie changed it into A Note for Acknowledging Princess Anji's Reward and collected it into "Notes". For the collection of this genre, both of Mei and Zhang had their own advantages and disadvantages respectively.

Letters: Mei Dingzuo compiled 23 letters, which are respectively: Letter to Xiangdong King Wang Yi, Letter to Acknowledge Xiangdong King Qing Zhoumu, Letter to Acknowledge Xiangdong King Wang Xizhi, Report to Xiangdong King, Letter to Answer Nanping King's Heir Wang Xiangwu, Letter to Answer Xinyuhouhe, Letter to Warn Dangyanggong daxin, Letter to answer Anji princess xianghuzi yitou, Letter to Liuxiaozhuo, Letter to answer Zhangcuanxie, Letter to Xiaolinchuan, Letter go answer Xiaoziyun shangfei baishuping, Letter to answer xuli, Letter to secretariat of Jingzhou named Li Zhi, Letter to answer Xiangdong King, Another letter to answer Xiangdong King, Letter to Guangxinhou for listening the fact, Letter go Guangxinhou for Repeating the fact. Letter to Huidan mage, Another letter to huidan mage, Wu book for Diaodao chengfa mage, Another Wu book for diaodao chengfa mage. Zhangfan did not receive the Report to Xiangdong King, Letter to Xuli, Letter to answer Jian princess, made Letter to Huidan mage, Another letter to Huidan mage together. Named it Two letter to Zhidan mage. According to Letter to Xiangdong King, Meidingzuo wrote Preview of Taiping, see the new old volume five nie fiveiii, it said, Jingshi said: discussing should like Xiangdong King, Office should like Wangke, the fact that preview was from Golden building ,in the notes. There is the book named Golden building in Ming wrote by Xiaogang, Meidingzuo wrote the notes for Letter to Xuli in Report Beilu. According to the writer, it was the proliferation of Letter to answer Xuli, and saved in Report Shuxuan by Liutangshou in Report Beilu. Meidingzuo divided it into two part ,and it was not wrong, and it was also right to record by Zhangfanfa. Letter to answer Anji princess was brought to note, We knew that the main reason for the difference is the loss test of Zhangfa, the type of this article was another reason, In the record ,Zhang and Mei both had the disadvantage and advantage.

Sequence: Series of article 13 by Meidingzuo, the golden Chun fu, regret fu, eye pouch fu Ming, too subset sequence, the preface to Linan princess set, 3 piece water's preface, the preface to the slimming spectrum, the preface to play chess theory, the deep and remote Zhi TiBi, the preface to goodness sleep temple monument, the preface to god yamadera tablet, the solemn kun mage into 
reality on hydrophobic sequence of righteousness, eight GuanZhai system sequence. Zhang Xie uncollected gold Chun fu, regret fu, eye pouch fu Ming, the preface to play chess theory, the preface to goodness sleep temple monument, the preface to god yamadera tablet. According to gold Chun fu, regret fu, eye pouch fu Ming these three articles to make the fu, this and three fu are as a whole, Meidingzuo dissever fu sequence class wrong; The preface to goodness sleep temple monument, the preface to god yamadera tablet also sequence of monuments,Meidingzuo split into order is also wrong. Zhang Xie ascribe fu into fu and monument are more better. The preface to play chess theory is the sequence of play chess theory, however, because of it, when the order in the theory of sequence, Zhang Xie classified them as theory. The author thought it wrong. Such differences are caused by different genre standard. This kind of collection, Zhang Xie is superior than Mr Mei.

Prefaces: Inscription: Series of article 17 by Meidingzuo, namely line rain mountain inscription, the moon mountain inscription, book inscription, mirror inscription, gauze fan inscription, xiang gong temple inscriptions, good sleep temple inscription , the beautiful forest inscription, big love worship temple brake the inscription, Wu Jun stone inscription, the Buddha, Buddha Ming, the Buddha Buddha wen Ming, Liang An temple Buddha, Buddha inscription, Ming MiTuo figure of Buddha, Buddha inscription type, kasyapa Buddha inscription, who Buddha inscription. Mr Mei will be the Buddha, Buddha inscription in two, not completed, when close to a story. Zhang Xie uncollected xiang gong temple inscriptions, good sleep temple inscription\", the beautiful forest inscription, big love worship temple brake the inscription, Wu Jun stone inscription, and two for a Buddha Buddha Ming wen, and added rod tin Ming one. According to: xiang gong temple inscriptions, good sleep temple inscription this for two tablet inscriptions, as the monument part of Zhang Xie melding with the two tablet into the monument, The beautiful forest inscription found the word interpretation, I don't know why Zhang Xie do not accept. Big love worship temple brake the inscription ,see beautiful [1] in 785, the name is very clear, Zhang Xie loss test. The Meidingzuo Wu Jun stone inscription, explained note cloud suzhou government record, almost the original into the Ming. This article and Song can see that Zhenghu minister wu all Wen Cui volume 7, the topic is fujiang float stone like Ming, a circumstantial evidence. Zhang Xie Wu Jun stone table into the memorial class or don't have this. These differences are mainly due to the different genre standards. Such plum, Zhang Ershi has advantages and disadvantages.

Inscriptions: Stone: Series of article 3 by Meidingzuo , for the prime minister king of changsha xuanwu tablet, the king of changsha xuanwu north liangzhou temple monument, Wu Xing king chu temple monument. Zhang Xie increase 6 article, namely good sleep temple monument, god yamadera tablet, goodness sleep temple monument, phase palace temple monument, Wu Jun stone tablet, recruit true GuanBei, but he will be the prime minister king of changsha xuanwu tablet topic as the king of changsha xuanwu inscriptions into epitaph is wrong, so the article can be found in the art type, volume four or five, to be the prime minister king of changsha xuanwu tablet. According to : good sleep temple monument, god yamadera tablet, Meidingzuo to its sequence into order; Phase goodness sleep temple monument, palace temple monument is for inscription article last part belong to the Ming. But this is four tablet category, Meidingzuo according to different genre standard treatment, real wrong. Zhang Xie are under the control of stone is the concept of genre is very accurate. Recruit true GuanBei an article by Zhang Xie found that its this article take the gusu tzu, yue recruit really the governance. Governance, wood road book says: 24 up and down method to heirs pay that cloth. After all stand in the xuan, therefore calls also. According to Chen horse pick Taoism biography .Zhang Yuqi recruit true pavilion, beam JianWen for tablet, this is along the yue recruit true GuanBei. And yue: the art type section of words in the Ming, said liang JianWen recruit true pavilion inscription, as JianWen pen. Undoubtedly the gusu volunteers and correct for it brought, this is it (see the beam JianWen emperor drive makes set matters Zhang Xie textual criticism), you can see that this kind of differences in addition to the genre standard is different, also is related with the amount according to the literature respectively. In comparison, Zhang Xie is superior than Mr Mei's.

Stele: Theory: Meidingzuo album urged the medical theory in 1 piece. Zhang Xieze ranked the preface to play chess theory, not as before (see before). 


\section{References}

[1] Write by Ouyangxun, correct by Wangshaoying in art collection. Shanghai guji press,1999.

[2] See page 279 in Xiaogang xiaoyi annual pu by Wguangxing. Social and technological press, 2006

[3] Write the Preview of Taiping by Lifang. Zhonghua publishing house, 1998

[4] Golden building wrote by Xiaoze. Zhonghua publishing house named the beginning of series integration, 1985

[5] Preview of Taiping wrote by Lifang. Zhonghua publishing house, 1960

[6] The beautiful wrote by Lifang. Zhonghua publishing house,1966 